\title{
Editor's Introduction: Science, Teaching and Robert K. Merton
}

\author{
Lawrence T. Nichols
}

Published online: 15 May 2010

(C) Springer Science+Business Media, LLC 2010

In this issue, we offer a wide-ranging set of papers, most of which have some connection with Robert K. Merton or with significant aspects of his published work. The timing of these contributions is most appropriate, for July 4, 2010 is Merton's centennial. I myself had the great good fortune to become acquainted with Merton through correspondence, and subsequently became the recipient of his marginalia on papers that I shared with him. Merton seems to have been naturally drawn to the role of mentor, initially with regard to his own students but later on a much broader scale that benefited colleagues with no formal claim upon his time and talent. For me, this will always be an especially memorable example of what I have called "intergenerational solidarity in the development of science."

We begin with an eyewitness account of Merton's famous course at Columbia University, Sociology 215-216, by Robert M. Marsh. Drawing upon his own student notes, Marsh takes readers through the course, step by step, while explicating its overall objectives and themes, many of which focused on the functional paradigm that Merton was then helping to create.

Raymond M. Lee offers another guided tour, this time through the diffusion of focus group methodology. Along the way, he examines in detail the reception of the 1956 book, The Focused Interview, by Merton, Marjorie Fiske and Patricia L. Kendall. Lee emphasizes the broad, interdisciplinary and international appeal of the method, and raises the question whether Merton himself may have experienced the "obliteration by incorporation" to which he called attention in his sociological studies of science.

Milan Zafirovski next provides a thoughtful conceptual paper that reexamines some of Merton's most influential ideas. Responding to "the Merton thesis" on the role of religion in the history of modern science, he examines whether contemporary religious conservatism, like the earlier Puritanism examined by Merton, should be

L. T. Nichols $(\bowtie)$

Division of Sociology and Anthropology, West Virginia University, Morgantown, WV, USA

e-mail: Larry.Nichols@mail.wvu.edu 
considered a functional analogue of fascism. In this updated form, Zafirovski argues, Merton's ideas remain relevant for our times.

Andrew Abbott follows with a provocative, programmatic essay grounded in his specialty field of the sociology of professions. His discussion of "varieties of ignorance" resonates with Merton's theme of "the specification of ignorance" in the development of science, to which Abbott responds as he develops his own conceptual framework of amateur ignorance, professional ignorance and expert ignorance.

Cecil Willis, finally, contributes to an ongoing conversation about sociologists as administrators, which was the theme of a recent issue of this journal. Reflecting on his own surprising odyssey from dissident assistant professor to high-echelon administrator, Willis takes readers "to the dark side and back." Interestingly, Merton seems to have taken a similar journey, but in reverse. At a relatively young age, he served briefly as a sociology department chair at Tulane University, but thereafter he generally avoided administrative duties in favor of teaching and scholarship. Readers who have themselves shouldered stressful and thankless administrative chores may well wonder whether Merton's choice here helps explain his rather remarkable longevity and productivity. 